\title{
SHORT-TERM OUTCOME OF INTRAVENOUS IRON THERAPY FOR IRON DEFICIENCY ANAEMIA AT JNIMS, IMPHAL- A PRELIMINARY REPORT
}

\author{
T. Ginzaniang1, Irom Anil Singh ${ }^{2}$, Ch. Arunkumar Singh ${ }^{3}$, P. Vedanti Devi ${ }^{4}$, Kh. Yoihenba ${ }^{5}$, Athui Gangmei ${ }^{6}$, T. Rebika Devi ${ }^{7}$
}

${ }_{1}^{1}$ Associate Professor, Department of Medicine, JNIMS, Imphal East, Manipur, India.

${ }^{2}$ Assistant Professor, Department of Medicine, JNIMS, Imphal East, Manipur, India.

${ }_{3}^{3}$ Assistant Professor, Department of Medicine, JNIMS, Imphal East, Manipur, India.

${ }_{4}^{4}$ Assistant Professor, Department of Medicine, JNIMS, Imphal East, Manipur, India.

${ }^{5}$ Senior Resident, Department of Medicine, JNIMS, Imphal East, Manipur, India.

${ }^{6}$ Senior Resident, Department of Medicine, JNIMS, Imphal East, Manipur, India.

${ }^{7}$ Postgraduate Trainee, Department of Medicine, JNIMS, Imphal East, Manipur, India.

\section{BACKGROUND}

ABSTRACT

Iron deficiency anaemia (IDA) comprises of 50\% of anaemia cases worldwide. The treatment consists of oral iron therapy and IV iron therapy. However, both of them may have their own side effects. Oral iron may have gastritis and constipation, while IV may have hypersensitive reaction.

\section{MATERIALS AND METHODS}

The study was conducted at the Department of Medicine, JNIMS, Imphal from July 2017 till March 2018. The study was an observational study. The aim of the study was to see the efficacy, indications and adverse effects of intravenous iron therapy in iron deficiency anaemia at JNIMS. The study included all patients with iron deficiency anaemia who received IV iron, either Ferric carboxymaltose or Iron isomaltoside during the study period.

\section{RESULTS}

Fifty-six patients of anaemia were diagnosed to have iron deficiency anaemia during the study period. Twenty patients were eligible for intravenous iron therapy. Remaining patients were on oral iron supplement. The commonest cause for IDA was heavy uterine bleeding (HUB) (50\%) followed by haemorrhoids (30\%). The indication for IV iron was commonest among patient with oral iron intolerance along with HUB (35\%). The baseline haemoglobin level in our study was $6.24 \pm 1.45 \mathrm{~g} / \mathrm{dL}$. Haemoglobin level at the end of 4 weeks and 3 months were $8.38 \pm 1.34 \mathrm{~g} / \mathrm{dL}$ and $12.98 \pm 0.75 \mathrm{~g} / \mathrm{dL}$ respectively. Six patients $(30 \%)$ had palpitation, dizziness and breathlessness lasting for 5 minutes immediately after the infusion. All the patients could finish IV iron.

\section{CONCLUSION}

Intravenous iron therapy is an essential treatment modality for the iron deficiency anaemia. Even with minor hypersensitive reactions, all the patients could continue the treatment with IV iron. All the cases had improved haemoglobin level at 4 weeks and 3 months.

\section{KEY WORDS}

Iron Deficiency Anaemia, Ferric Carboxymaltose, Iron Isomaltoside.

HOW TO CITE THIS ARTICLE: Ginzaniang T, Singh IA, Singh CA, et al. Short-term outcome of intravenous iron therapy for iron deficiency anaemia at JNIMS, Imphal- a preliminary report. J. Evolution Med. Dent. Sci. 2018;7(23):2728-2731, DOI: $10.14260 /$ jemds/2018/616

\section{BACKGROUND}

Anaemia is a major health problem affecting both developing and developed countries. Approximately, $50 \%$ of the cases of anaemia are due to iron deficiency, but the proportion may vary among population groups and in different areas according to the local conditions. The main risk factors for iron deficiency anaemia (IDA) include a low intake of iron, poor absorption of iron from diets high in phytate or phenolic compounds, and period of life when iron requirements are especially high (i.e. growth and pregnancy).(1)

'Financial or Other Competing Interest': None.

Submission 21-04-2018, Peer Review 21-05-2018,

Acceptance 28-05-2018, Published 04-06-2018.

Corresponding Author:

Irom Anil Singh,

Clinical Haematology,

Department of Medicine,

JNIMS, Porompat, Imphal East-795005,

Manipur, India.

E-mail: anilirom@gmail.com

DOI: $10.14260 /$ jemds $/ 2018 / 616$

Conventionally, dietary supplements, oral iron and iron sucrose were the treatment for IDA. Historically, many physicians' concerns about intravenous iron are the severe infusion reactions associated with high-molecular-weight iron dextran. Later, various iron salts with lesser side effects became available to the patients like ferric gluconate and iron sucrose. The major drawback was because of the fact that the carbohydrate shells in them bind iron less tightly. So it can bind a small dose of $250 \mathrm{mg}$ at a time and it had to be given weekly in multiple sittings.(2) Now, single dose iron preparations are changing the treatment scenarios. These newer iron preparations are approved for use by competent authorities in many parts of the world and at the same time can be administered within a short duration. They are lowmolecular-weight iron dextran (1 hr), ferumoxytol (15 mins), ferric carboxymaltose (15 mins) and iron isomaltoside (15 mins). The carbohydrate shells in these preparations bind elemental iron more tightly. Resultantly, adverse effects are much reduced and the complete replacement doses can be given safely in 15 mins to one hour.(2) We wanted to study the 
profile of patients receiving IV iron at JNIMS, Imphal which is located at North Eastern part of India.

\section{MATERIALS AND METHODS}

The study was conducted at the Department of Medicine JNIMS, Imphal from July 2017 till March 2018. The study was an observational study. The aim of the study was to see the efficacy, indications and adverse effects of intravenous iron therapy in iron deficiency anaemia at JNIMS. All the consecutive IDA patients attending JNIMS Medicine OPD were eligible for the study. The study included all the patients who received IV Iron either Ferric carboxymaltose or Iron isomaltoside. The patients were excluded if they were taking oral iron, iron sucrose or not giving consent. The diagnosis of anaemia was made if the haemoglobin level was below the normal as per WHO definition of anaemia (male $<13 \mathrm{~g} / \mathrm{dL}$, women $<12 \mathrm{~g} / \mathrm{dL}$ or pregnancy $<11 \mathrm{~g} / \mathrm{dL}$ ). Iron deficiency anaemia was diagnosed when the serum ferritin level was less than lower limit of normal or transferrin saturation ratio $<16 \%$ in case of normal ferritin level. Serum electrolytes, KFT and LFT were done as a part of routine investigation. Upper GI endoscopy was done for elderly patients and postmenopausal women. The indication for IV iron was as per the standard guidelines. They were oral iron intolerance, heavy uterine bleeding who required relatively faster improvement for undergoing surgery and those who wished to avoid prolonged treatment with oral iron. After taking consent, the patients were given IV iron in OPD. Premedication with hydrocortisone and pheniramine maleate was given routinely to all the patients. The IV iron was given as per the standard guidelines over $15 \mathrm{mins}$ for $500 \mathrm{mg}$. A maximum of $1000 \mathrm{mg}$ was given on a single setting. If the patient developed hypersensitive reaction, the injection was withheld. Patients were diagnosed to have hypersensitive reaction if they complained of palpitation, breathlessness or dizziness. We gave normal saline $100 \mathrm{~mL}$ and restart the infusion after 15 mins. Haemoglobin level was checked at 4 weeks, 3 months and 6 months. Since the study is a preliminary study, the sample size was small. As a result of which statistical analysis could not be performed. Mean \pm SD was calculated to see the response of treatment.

\section{RESULTS}

Fifty-six patients of anaemia were diagnosed to have iron deficiency anaemia during the study period. Twenty patients were eligible for intravenous iron therapy. Remaining patients were on oral iron supplement.

Baseline characteristics of the patients in the study are shown in Table No. 1 . The maximum number of patients $(55 \%)$ requiring IV iron were in the age group of $30-50$ years. The women consisted of $65 \%$. The commonest cause for IDA was heavy uterine bleeding (50\%) followed by haemorrhoids (30\%). The indication for IV iron was commonest with oral iron intolerance along with HUB (35\%), relatively quicker response for impending surgery (30\%), to avoid prolonged treatment with oral iron $(20 \%)$, oral iron intolerance (10\%) and heavy uterine bleeding (5\%).

The response to therapy was studied at 4 weeks and 3 months. It is shown in Table No. 2. The mean baseline haemoglobin level in our study was $6.24 \pm 1.45 \mathrm{~g} / \mathrm{dL}$ with a range of $4.5-9.8 \mathrm{~g} / \mathrm{dL}$. At the end of 4 weeks, all the patients had shown increment in haemoglobin level. The mean haemoglobin level was $8.38 \pm 1.34 \mathrm{~g} / \mathrm{dL}$ with a range of 6.2 $11.2 \mathrm{~g} / \mathrm{dL}$. At the end of three months, the haemoglobin level was $12.98 \pm 0.75 \mathrm{~g} / \mathrm{dL}$ with a range of $11.2-14 \mathrm{~g} / \mathrm{dL}$.

The infusion of iron was associated with some hypersensitive reactions. Six patients (30\%) had palpitation, dizziness and breathlessness lasting for 5 mins immediately after the infusion. All of them were given repeat premedications. The infusion was stopped for 5 mins. Normal saline $100 \mathrm{~mL}$ was given and remaining dose of IV iron was given slowly over 30 mins through the sidearm of normal saline. All six of them could finish despite mild hypersensitive reactions.

\begin{tabular}{|c|c|}
\hline Baseline Characteristics & (n= 20) (\%) \\
\hline Age (yrs.) & $5(25 \%)$ \\
$10-30$ & $11(55 \%)$ \\
$30-50$ & $1(5 \%)$ \\
$50-70$ & $3(15 \%)$ \\
$>70$ & $7(35 \%)$ \\
Male & $13(65 \%)$ \\
Female & $10(50 \%)$ \\
Causes & $3(15 \%)$ \\
Heavy Uterine Bleeding (HUB) & $6(30 \%)$ \\
Upper GI bleeding & $1(5 \%)$ \\
Haemorrhoids & $2(10 \%)$ \\
Unknown & $1(5 \%)$ \\
Indications for IV iron & $7(35 \%)$ \\
Oral iron intolerance & $4(20 \%)$ \\
HUB & $6(30 \%)$ \\
Oral iron intolerance + HUB & To avoid prolong treatment \\
Relatively quicker response & Table 1. Baseline Characteristics \\
\hline \multicolumn{2}{|c|}{}
\end{tabular}

\begin{tabular}{|c|c|}
\hline Hb (g/dL) Response & Mean \pm SD (Range) \\
\hline Baseline & $6.24 \pm 1.45(4.5-9.8)$ \\
\hline 4 weeks & $8.38 \pm 1.34(6.2-11.2)$ \\
\hline 3 months & $12.98 \pm 0.75(11.2-14)$ \\
\hline \multicolumn{2}{|c|}{ Table 2. Hb Response to IV Iron } \\
\hline
\end{tabular}

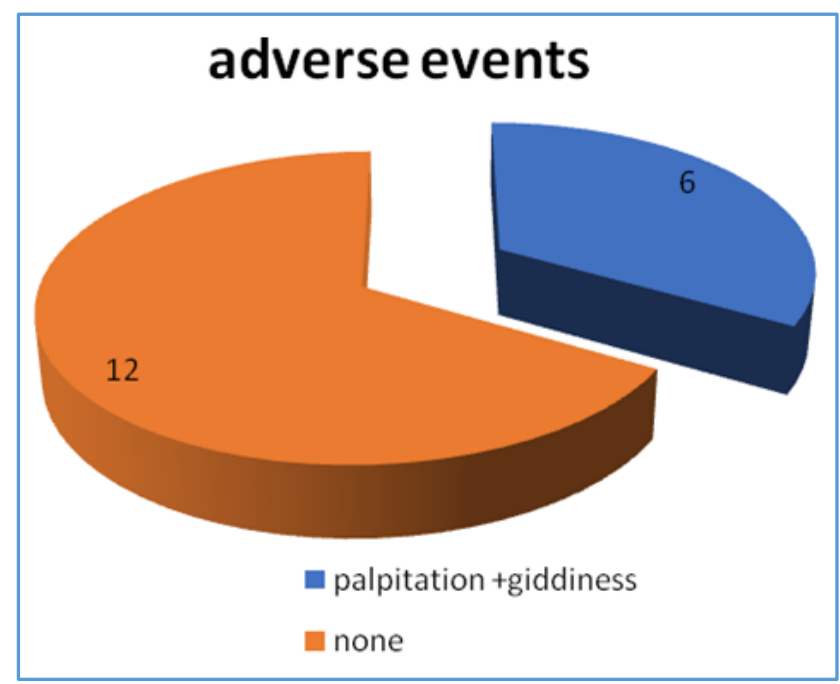

Figure 1. Adverse Effects

\section{DISCUSSION}

Parenteral iron (IV-iron) has become an important treatment for iron deficiency anaemia in a wide range of therapeutic areas when oral iron is inappropriate, ineffective or not 
tolerated. The newer iron preparations can be administered within a short duration. The new formulations are:

1. Low-molecular-weight iron dextran (01 hour).

2. Ferumoxytol (15 minutes).

3. Ferric carboxymaltose (15 minutes).

4. Iron isomaltoside (15 minutes).

The carbohydrate shells in these preparations bind elemental iron more tightly. Resultantly, adverse effects are much reduced and the complete replacement doses can be given safely in 15 minutes to 1 hour. In 2013, FDA approved ferric carboxymaltose. In Europe it is given in the dosage of $1000 \mathrm{mg}$ in 15 minutes, whereas in the USA $750 \mathrm{mg}$ single dose or $1500 \mathrm{mg}$ in two visits is given. It is approved for use in pregnancy, in patients intolerant of or unresponsive to oral iron and conditions in which oral iron is prescribed. Iron isomaltoside was approved for use in Europe in 2009, but it is yet to be approved in the US. The preparation has got a unique matrix structure, which ensures high stability of the compound similar to Ferumoxytol and FCM. It again releases the labile-free iron in limited quantities. Further, it allows rapid infusion of a high dose up to a maximum dose of 20 $\mathrm{mg} / \mathrm{kg}$ of body weight without any test dose.(2) In our study, we gave either ferric carboxymaltose or isomaltoside randomly. As per standard guidelines, we also gave a maximum of $1000 \mathrm{mg}$ in a sitting. All the patients in our study however needed only one sitting.

There may be hypersensitive reactions (HRS) to the infusion. The symptoms and their organ expression do not seem to differ between IV-iron and other drugs. HSRs may range from mild-to-severe, life-threatening reactions can occur with either IV-iron formulation or any other IV drugs. It can be acute, short, delayed or extended. The prevalence of HSRs to different IV-iron preparations is very low, a feature shared only with the safest radiocontrast agents.(3) A metaanalysis done on the safety of intravenous iron preparations showed that there can be infusion reactions with intravenous iron, but there was no increase in the serious adverse effects. Marked reduction in gastrointestinal toxicity was also observed. The study concluded that intravenous iron formulations are safe and well tolerated and should be an alternative to red blood cell transfusion.(4) Misra et al had reported from Ahmedabad about the safety of ferric carboxymaltose. In their study, out of the 615 women 595 women were included in the analysis. Most of the women were in the age group of 27 - 30 years. No serious adverse events were observed after Ferric Carboxymaltose. They concluded that intravenous Ferric Carboxymaltose was an effective and a safe treatment option for iron deficiency anaemia and has an advantage of single administration of high doses without serious adverse effects.(5) Naqash A et al had reported from Jammu and Kashmir about 200 patients at Department of Obstetrics and Gynaecology, Sher-I-Kashmir Institute of Medical Sciences Medical College and Hospital, Jammu and Kashmir, India identified with IDA. Intravenous FCM and Iron Sucrose (IS) were both given as per the protocol. They also observed no serious adverse effects. They also concluded parenteral therapy as an effective treatment in IDA with minimum adverse drug reactions. (6) Misra et al also reported a prospective study in Ahmedabad among antenatal women (108) with iron deficiency anaemia. Intravenous ferric carboxymaltose as per total correction dose (maximum $1500 \mathrm{mg}$ ) was administered to all women and they found that mean haemoglobin levels significantly increased over a period of 3 weeks after Ferric carboxymaltose administration and no serious lifethreatening adverse events were observed. They concluded that intravenous ferric carboxymaltose was safe and effective in pregnant women with iron deficiency anaemia.(7) In our study, there was hypersensitive reaction. The incidence was $30 \%$ in our study. One of the six patients with hypersensitive reactions had delayed as well acute reactions. However, all of them could complete the infusion after giving pheniramine maleate, hydrocortisone and IV fluids. The higher incidence may have been due to lower study population.

Michael Auerbach et al did a study by administering LMWID to 888 female patients, who were intolerant to oral iron. It was found that heavy uterine bleeding was the commonest indication, $\mathrm{Hb}$ or haematopoietic response was more than $85 \%$ and there was no clinically significant adverse event.(2) In our study, the commonest indication was oral iron intolerance and coexisting heavy uterine bleeding (35\%). The next common indication was group of patients who wanted relatively quicker response for impending surgery or delivery (30\%). There was $20 \%$ of patient who wish to get IV iron to avoid long-term oral iron therapy. This IV formulation may be cost effective in long term, because it avoids regular frequent visits and side effects of the oral iron are avoided.

In the study by Ayub et al, these new formulations were given to pregnant women. Haemoglobin $(\mathrm{Hb})$ level was found to be improved by $1-1.9 \mathrm{gm} / \mathrm{dL}$ in $82 \%$ and more than 2 $\mathrm{gm} / \mathrm{dL}$ in $24 \%$ of the recipients. Anaemia was resolved in $95 \%$ of the study subjects. These results were consistent across the spectrum of published evidence. Hence, in pregnant women having iron deficiency anaemia intravenous iron should be administered as soon as oral iron intolerance occurs or if oral form is found to be ineffective or harmful.(8) Misra et al had reported that mean haemoglobin levels had significantly increased over a period of three weeks after Ferric Carboxymaltose administration.(5) Naqash A et al had reported from Jammu and Kashmir a significant increase in the mean $\mathrm{Hb}$ was observed from $7.76 \pm 0.709$ to $13.25 \pm 0.606$ in patients treated with FCM and $7.64 \pm 0.710$ to $11.59 \pm 0.733 \mathrm{~g} / \mathrm{dL}(\mathrm{p}<0.001)$ in patients treated with IS after four weeks of therapy.(6) In our study, only 2 patients were pregnant. The rise in haemoglobin level was adequate and by third month $100 \%$ patients achieved normal haemoglobin level. The response to IV iron may be more robust in this part of the country due to various host factors. In our study by 4 weeks, haemoglobin improved by more than $2 \mathrm{~g} / \mathrm{dL}$ and by 3 months more than $6 \mathrm{~g} / \mathrm{dL}$. This could be due to the fact that in western countries, the treatment for anaemia is started early when the haemoglobin levels dropped to about $9 \mathrm{~g} / \mathrm{dL}$. Whereas in Manipur and other states of India, the patients usually come when the haemoglobin level is quite low. This may be one of the reasons for greater improvement in haemoglobin level.

\section{Strength of the Study}

This is the first preliminary report of single IV preparations in the treatment of IDA in the state of Manipur. Limited data is available with respect to comparison of safety and efficacy of single IV iron preparations from this part of the country. This 
study gives an insight about the adverse effects and the data is reliable, as it was progressively collected and documented during and after the treatment. Further enrolment is still going on and the bigger sample size may give a better picture.

\section{Limitation of the Study}

The number of patients and duration of study was less. The study needs to be done on a larger population (both male and female and all age groups) and the time duration needs to be more to assess the long-term effects of these drugs. Comparison also needs to be done with oral formulation and other preparations like iron sucrose.

\section{CONCLUSION}

Intravenous iron therapy is an essential treatment modality for the iron deficiency anaemia. Even with minor hypersensitive reactions, all the patients could continue the treatment with IV iron. All the cases had improved haemoglobin level at 4 weeks and 3 months.

\section{REFERENCES}

[1] WHO. Worldwide prevalence of anaemia 1993-2005. http://www.who.int/nutrition/publications/micronut rients/anaemia_iron_deficiency/9789241596657/en/

[2] Auerbach M, Deloughery T. Single-dose intravenous iron for iron deficiency: a new paradigm. Hematology Am Soc Hematol Educ Program 2016;2016(1):57-66.
[3] Szebeni J, Fishbane S, Hedenus $M$, et al. Hypersensitivity to intravenous iron: classification, terminology, mechanisms and management. $\mathrm{Br} \mathrm{J}$ Pharmacol 2015;172(21):5025-36.

[4] Avni T, Bieber A, Grossman A, et al. The safety of intravenous iron preparations: systematic review and meta-analysis. Mayo Clin Proc 2015;90(1):12-23.

[5] Mishra V, Roy P, Gandhi K, et al. Safety and efficacy of intravenous ferric carboxy maltose in iron deficiency anaemia during post-partum period. J Nepal Health Res Counc 2018;15(3):208-11.

[6] Naqash A, Ara R, Bader GN. Effectiveness and safety of ferric carboxymaltose compared to iron sucrose in women with iron deficiency anemia: phase IV clinical trials. BMC Womens Health 2018;18(1):6.

[7] Mishra V, Gandhi K, Roy P, et al. Role of intravenous ferric carboxy-maltose in pregnant women with iron deficiency anaemia. J Nepal Health Res Counc 2017;15(2):96-9.

[8] Ayub R, Tariq N, Adil MM, et al. Efficacy and safety of total dose infusion of low molecular weight iron dextran in the treatment of iron deficiency anemia during pregnancy. J Coll Physicians Surg Pak JCPSP 2008;18(7):424-7. 